\title{
ESTUDO DA ADIÇÃO DE VITAL GLÚTEN À FARINHA DE ARROZ, FARINHA DE AVEIA E AMIDO DE TRIGO NA QUALIDADE DE PÃES ${ }^{1}$
}

\author{
Guilherme de A. S. TEDRUS², Rita de Cássia S. Celeste ORMENESE ${ }^{3}$, \\ Sandra Maria SPERANZA ${ }^{3}$, Yoon K. $\mathrm{CHANG}^{4},{ }^{*}$, Fernando M. BUSTOS ${ }^{5}$
}

\begin{abstract}
RESUMO
Farinhas de arroz e de aveia e amido de trigo foram adicionados de vital glúten e avaliados pelo Teste de Panificação. Usou-se como padrão uma amostra de farinha de trigo com características adequadas para produção de pão. Os níveis de adição de vital glúten foram de 10,15, 17,5, 20 e $30 \%$ para a farinha de arroz e de 10, 20 e 30\% para a farinha de aveia. Ao amido de trigo, extraído da farinha de trigo utilizada como padrão, foi adicionado vital glúten de forma a reconstituir o teor de glúten original da farinha. Os melhores resultados do teste de panificação foram obtidos com $17,5 \%$ de vital glúten na farinha de arroz e $20 \%$ de vital glúten na farinha de aveia. Foram obtidos pães com volumes específicos inferiores aos de trigo $\left(2,67 \mathrm{~cm}^{3} / \mathrm{g}\right.$ para vital glúten + farinha de arroz, $3,07 \mathrm{~cm}^{3} / \mathrm{g}$ para vital glúten + farinha de aveia e $4,14 \mathrm{~cm}^{3} / \mathrm{g}$ para vital glúten + amido de trigo contra $5,15 \mathrm{~cm}^{3} / \mathrm{g}$ para os de farinha de trigo). As melhores misturas foram analisadas quanto às suas características reológicas e comparadas com a farinha de trigo original. A mistura de amido de trigo e vital glúten apresentou características farinográficas extensográficas inferiores à farinha de trigo e deu origem a pães de menor volume e com estrutura compacta. No geral, a adição de vital glúten propiciou a obtenção de pães com características aceitáveis, embora inferiores às do pão de farinha de trigo. As características dos pães contendo vital glúten foram: pouca simetria e quebra praticamente inexistente. São necessários novos estudos sobre a interação do vital glúten com os demais componentes da farinha de trigo e sua influência na qualidade do produto final.
\end{abstract}

Palavras-chave: vital glúten; farinha de arroz; farinha de aveia; amido de trigo; pão.

\section{SUMMARY}

EFFECTS OF THE ADDITION OF VITAL GLUTEN TO RICE FLOUR, OAT FLOUR AND WHEAT STARCH ON THE QUALITY OF BREADS. Breadmaking Test was used to evaluate the quality of breads made of rice flour, oat flour and wheat starch with added vital gluten. A flour sample adequate for breadmaking was used as standard. The blends of rice flour had 10, 15, 17.5, 20 and $30 \%$ of vital gluten and the blends of oat flour had 10,20 and $30 \%$ of vital gluten. Vital gluten was also added to the starch

\footnotetext{
${ }^{1}$ Recebido para publicação em 22/12/99. Aceito para publicação em 03/04/01.

${ }^{2}$ Aluno de Pós-graduação, Curso Técnico de Alimentos - SENAI, CEP 13041-670, Campinas, SP.

${ }^{3}$ Aluna de Pós-graduação, Instituto de Tecnologia de Alimentos, C.P. 139. CEP 13073-001, Campinas, SP.

${ }^{4}$ Professor, Departamento de Tecnologia de Alimentos - FEA UNICAMP, CP 6121, CEP 13083-970, Campinas, SP. Fone: (19) 3788-4001/3788-4004.E-mail:yokic@fea.unicamp.br

${ }^{5}$ Professor, Laboratorio de Investigación en Materiales. CINVESTAV-Querétaro, México.

${ }^{*}$ A quem a correspondência deve ser enviada.
}

extracted from the standard wheat flour in order to reconstitute the original flour wheat content. The best results from the Breadmaking Test were obtained with the blends of $17.5 \%$ of vital gluten to the rice flour and $20 \%$ of vital gluten to the oat flour. The breads obtained showed lower volume values than those made of wheat flour $\left(2.67 \mathrm{~cm}^{3} / \mathrm{g}\right.$ for vital gluten+rice flour, $3.07 \mathrm{~cm}^{3} / \mathrm{g}$ for vital gluten+oat flour and $4.14 \mathrm{~cm}^{3} / \mathrm{g}$ for vital gluten+wheat starch and $5.15 \mathrm{~cm}^{3} / \mathrm{g}$ for standard wheat flour). The rheological characteristics of the best blends were analyzed and compared to the standard wheat flour. The blend of vital gluten and flour starch showed inferior rheological characteristics than the original wheat flour. Also, their breads showed lower volume and compact structure. In general, breads with acceptable characteristics were obtained with the addition of vital gluten to rice flour, oat flour and wheat starch although these characteristics were inferior to those from the breads produced with the original wheat flour. Breads with vital gluten showed little symmetry and almost no breaking. New studies are necessary to investigate the interaction of vital gluten with the other components of wheat flour and its influence in the quality of the final product.

Keywords: vital gluten; rice flour; oat flour; wheat starch; bread.

\section{1 - INTRODUÇÃO}

Dentre as farinhas dos diferentes cereais, apenas a do trigo tem a habilidade de formar uma massa viscoelástica que retém o gás produzido durante a fermentação e nos primeiros estágios de cozimento do pão, dando origem a um produto leve. As proteínas, mais especificamente as formadoras do glúten, são as principais responsáveis por esta característica própria do trigo. O glúten é composto por duas frações protéicas: a gliadina e a glutenina. A gliadina apresenta um peso molecular médio de 40.000 , cadeia simples e é extremamente gomosa quando hidratada, apresentando pouca ou nenhuma resistência à extensão, e sendo portanto, responsável pela coesividade da massa. A glutenina é formada por várias cadeias ligadas entre si, apresentando um peso molecular médio que varia de 100.000 a vários milhões, é elástica, mas não coesiva e fornece à massa a propriedade de resistência à extensão [8]. Esse mesmo autor afirma que nenhum outro cereal apresenta proteínas com capacidade para a formação de massa como a do trigo. O centeio e o triticale, um híbrido de centeio e trigo, são os que mais se aproximam dessas características, porém suas massas ainda são mais fracas que a de trigo. Dois fatores determinam o volume do pão: a quantidade de gás produzido durante a fermentação e a capacidade de retenção desse gás pela massa. HE \& HOSENEY [7], em estudo realizado sobre o uso de farinhas de centeio, milho e arroz na produção de pão concluíram que a capacidade de retenção de gás é o principal fator para a obtenção de 
pães com volume adequado, visto que durante a fermentação, a perda de gás nas massas desses cereais foi de 3 a 5 vezes superior à da massa de farinha de trigo, embora a produção inicial de gás tenha sido semelhante. Durante o cozimento, ao contrário da massa de farinha de trigo, as massas de farinha de milho, arroz e centeio perderam gás antes que suas estruturas estivessem consolidadas pelo calor, apresentando como resultado final pães com baixo volume.

CAPRONI \& BONAFACCIA [4], ao analisarem o alveograma de farinha de trigo com adição de glúten seco na proporção de 3 a 5\%, concluíram que este aditivo conferiu valores maiores de elasticidade $(P)$ e de força $(W)$, além de uma relação $P / L$ mais equilibrada e constante. MAGNUSON [10] explica que as propriedades viscoelásticas do vital glúten melhoram a força da massa, a tolerância à mistura e propriedades de manuseio. Sua habilidade para formar filme proporciona uma melhor retenção de gás e uma expansão controlada, dando melhor volume, uniformidade e textura. Sua maior capacidade de absorção de água melhorou o rendimento do produto fermentado, sua maciez e vida-de-prateleira.

O vital glúten é um concentrado protéico (com cerca de $80 \%$ de proteína) na forma de pó de coloração branco-acinzentada quando extraído de massas de trigo. A Associação Internacional de Glúten de Trigo classifica o glúten como vital e não-vital. É classificado como não-vital quando tendo sofrido desnaturação irreversível, apresenta capacidade apenas de absorver água em quantidade relativa ao tamanho e distribuição de suas partículas. O vital glúten, quando em contato com água se reidrata rapidamente, readquirindo sua funcionalidade intrínseca [5].

O vital glúten é um aditivo utilizado na indústria de panificação. Seu uso é recomendado para a produção de alguns pães especiais (com adição de fibras, gérmen, uvas passas e outros ingredientes inertes), panetones em que a etapa de fermentação é longa e o volume é de grande importância, ou mesmo quando se utiliza farinha de trigo com baixa quantidade ou qualidade de glúten $[2,4,11]$.

A possibilidade do uso da farinha de arroz na produção de pães aumenta o valor agregado desta matéria-prima considerada subproduto do beneficiamento, uma vez que os grãos quebrados têm pouca utilização industrial. Quanto à aveia, o interesse por sua utilização na produção de pães se justifica por tratar-se do único cereal cuja proteína apresenta um balanço de aminoácidos interessante sob o ponto de vista nutricional, além do teor protéico ser superior ao dos demais cereais [8]. Sabe-se também que a aveia é capaz de reduzir os níveis de colesterol no plasma sanguíneo devido principalmente à fração solúvel de sua fibra alimentar ser rica em b-glucana [9].

Este trabalho teve como objetivo estudar a possibilidade da utilização de farinha de arroz e de farinha de aveia na produção de pão, com emprego de vital glúten determinando o nível necessário de adição desse aditivo, e verificar se o glúten poderia ser considerado o único responsável pela característica de formação de massa, própria do trigo, avaliando a reconstituição da farinha de trigo padrão com vital glúten.

\section{2 - MATERIAL E MÉTODOS}

\section{1 - Matérias-primas e ingredientes}

Foram utilizadas como matérias-primas as farinhas de arroz, de aveia e de trigo, que foram avaliadas quanto as suas características físico-químicas conforme metodologias oficiais [1,2]. Os perfis granulométricos foram determinados em jogo de peneiras vibratórias e a atividade enzimática medida pelo Falling Number [1]. As matérias-primas foram retiradas de um mesmo lote de produção.

Foram utilizados ainda vital glúten de marca comercial Rhodia e enzima $\alpha$-amilase fúngica de marca comercial Quest para a correção da atividade enzimática das farinhas estudadas.

\section{2 - Determinação da vitalidade do glúten}

Seguindo recomendações de CZUCHAJOWSKA \& PASZCZYÑSKA [6], amostras de vital glúten provenientes de três diferentes lotes de um mesmo fabricante (Rhodia S. A.) foram adicionadas na proporção de $5 \%$ a uma farinha de trigo com baixo teor de proteína (9\%). Essas misturas foram submetidas ao Teste de Panificação [6] para a determinação de sua vitalidade e seleção do glúten de melhor desempenho.

\section{3 - Uso das misturas de farinha de arroz e de aveia com vital glúten}

Inicialmente, o desempenho das misturas compostas de $80 \%$ de farinha de arroz ou de aveia com $20 \%$ de vital glúten na produção de pão de forma foi avaliado através do Teste de Panificação [6]. Utilizou-se a seguinte formulação: $300 \mathrm{~g}$ das misturas de farinha de arroz ou de aveia com vital glúten ( $14 \%$ base úmida), $15 \mathrm{~g}$ de açúcar, $9 \mathrm{~g}$ de fermento biológico, $9 \mathrm{~g}$ de gordura, $5,25 \mathrm{~g}$ de sal e $30 \mathrm{mg}$ de ácido ascórbico. A correção da atividade diastática das misturas foi feita conforme descrito no item 3.1. A massa foi preparada no misturador do farinógrafo e pesada em duas porções de $150 \mathrm{~g}$ cada uma. Essas massas foram boleadas, modeladas, postas em formas próprias e levadas à câmara de fermentação a $30^{\circ} \mathrm{C}$. Após 105 minutos, foram assadas em forno elétrico a $220^{\circ} \mathrm{C}$ por 20 minutos. A qualidade dos pães foi avaliada através dos seguintes parâmetros: volume específico $\left(\mathrm{cm}^{3} / \mathrm{g} \times 3,33\right)$, características externas (cor da crosta, quebra e simetria), características internas (da crosta, além da cor, estrutura e textura do miolo), aroma e sabor. A pontuação foi feita, conforme a importância do parâmetro avaliado na característica do pão.

Os resultados de todas as misturas avaliadas foram comparados com os obtidos a partir de uma farinha de trigo com características adequadas para a produção de pão. As misturas que apresentaram os meIhores resultados no Teste de Panificação foram anali- 
sadas em farinógrafo e extensógrafo [1] para a caracterização reológica e posterior comparação com as características da farinha de trigo.

2.4 - Extração do amido da farinha de trigo e sua reconstituição do teor de glúten original pelo vital glúten

A farinha de trigo utilizada como padrão foi lavada, utilizando-se solução salina $2 \%$ com o objetivo de extrair seu glúten. $\mathrm{O}$ amido assim obtido foi lavado com água corrente até que o sabor salgado não fosse perceptível sensorialmente. Em seguida, foi congelado a $-20^{\circ} \mathrm{C}$ e liofilizado. Os parâmetros de temperatura e tempo utilizados no processo de liofilização foram: $-15^{\circ} \mathrm{C}$ por 4 horas; $0^{\circ} \mathrm{C}$ por 14 horas e $25^{\circ} \mathrm{C}$ por 6 horas. Durante o período do processo, a pressão variou de 3,5 a 1,0 $\mathrm{mm} \mathrm{Hg}$. $\mathrm{O}$ amido liofilizado foi moído e apresentou granulometria inferior a $212 \mathrm{~mm}$. Adicionou-se vital glúten de forma a reconstituir o teor de glúten seco original da farinha de trigo (10,3\%) conforme Tabela 1.

A atividade enzimática da mistura amido de trigo + vital glúten medida pelo "Falling Number" [1] foi de 333 segundos. Após correção através da adição de enzima $\alpha$-amilase, obteve-se valor de "Falling Number" de 241 segundos, próximo portanto do recomendado por HE \& HOSENEY [7].

A mistura assim obtida foi analisada em farinógrafo e extensógrafo [1] para a caracterização reológica e posterior comparação com as características da farinha de trigo. Seu desempenho na produção de pão foi avaliado através do Teste de Panificação [6].

\section{3 - RESULTADOS E DISCUSSÃO}

\section{1 - Caracterização das farinhas}

As farinhas de trigo, de arroz e de aveia foram caracterizadas físico-quimicamente, conforme resultados apresentados na Tabela 1.

TABELA 1. Valores médios da composição química das farinhas de trigo, arroz e aveia

\begin{tabular}{|c|c|c|c|}
\hline \multirow[t]{2}{*}{ Composição (\%) } & \multicolumn{3}{|c|}{ Farinha } \\
\hline & Trigo & Arroz & Aveia \\
\hline Umidade $^{1}$ & $11,73(0,10)$ & $5,38(0,007)$ & $8,98(0,09)$ \\
\hline Cinzas $^{1}$ & $0,35(0,002)$ & $0,74(0,001)$ & $3,38(0,001)$ \\
\hline Proteínas ${ }^{1}$ & $11,21(0,13)$ & $6,83(017)$ & $12,14(0,17)$ \\
\hline Glúten seco ${ }^{2}$ & $10,3(0,20)$ & - & - \\
\hline Gordura $^{3}$ & $1,33(0,02)$ & $0,89(0,06)$ & $7,61(0,03)$ \\
\hline Carboidratos $^{4}$ & 75,38 & 86,16 & 67,89 \\
\hline
\end{tabular}

1AACC 44-15A, 08-01, 46-12 [1]. Valores médios de 3 repetições. ${ }^{2} A A C C$ 38-12[1]. Valores médios de 2 repetições.

${ }^{3} A O A C[$ [2.]. Valores médios de 3 repetições.

Desvio padrão

As análises de granulometria realizadas na farinha de trigo indicaram uma concentração na faixa abaixo de $125 \mathrm{~mm}$. A farinha de arroz apresentou uma granulometria intermediária, entre 125 e $212 \mathrm{~mm}$ e a farinha de aveia apresentou-se como a mais grossa, concentrando-se acima de $212 \mathrm{~mm}$.
As atividades enzimáticas das farinhas de trigo, de aveia e de arroz medidas pelo "Falling Number" [1] foram de 329, 421 e maior do que 1000 segundos, respectivamente. Para uso no Teste de Panificação, as atividades enzimáticas da farinha de trigo e das misturas de farinha de arroz com vital glúten foram corrigidas para 236 e 237, respectivamente, valores próximos dos 220 segundos recomendados por HE \& HOSENEY [7]. Para as misturas de farinha de aveia com vital glúten, os valores obtidos de "Falling Number" foram muito discrepantes (70 e 423, para cada uma das duplicatas), possivelmente devido à não uniformidade do tamanho das partículas da mistura, o que impossibilitou a correção da atividade diastática.

\section{2 - Determinação da vitalidade do glúten}

Das três amostras avaliadas, a A foi a que conferiu aos pães maior volume específico (5,81 contra 5,27 e $5,36 \mathrm{~cm}^{3} / \mathrm{g}$ obtidos, respectivamente, para as amostras B e C). Conseqüentemente, essa amostra obteve também maior pontuação total no Teste de Panificação (82,8 contra 80,5 e 80,3 das amostras B e C), sendo então, a selecionada para a composição das misturas com as farinhas de arroz e de aveia.

Variações na qualidade do vital glúten desidratado podem ocorrer tanto em função das características do trigo, a partir do qual foi extraído, como também devido às mudanças ocorridas durante o processo de produção. O ponto mais crítico na preparação é a etapa de secagem por requerer energia térmica, podendo o vital glúten úmido perder a sua vitalidade devido à grande susceptibilidade à desnaturação quando exposto à alta temperatura [12].

3.3 - Avaliação da qualidade panificável das misturas de farinha de arroz e de aveia com vital glúten por meio do Teste de Panificação

A partir dos resultados obtidos através da avaliação do desempenho das misturas compostas de $80 \%$ de farinha de arroz ou de aveia com $20 \%$ de vital glúten através do Teste de Panificação [6], misturas com acréscimo e com decréscimo de $50 \%$ de vital glúten foram preparadas. Essas misturas também foram avaliadas pelo Teste de Panificação [7], obtendo-se então, para a mistura de farinha de aveia, a proporção considerada mais adequada (Tabela 3 ). Em relação à mistura com farinha de arroz, conforme os resultados descritos na Tabela 2, foram realizados dois ensaios intermediários de redução de vital glúten (25 e 37,5\%) para a obtenção da proporção mais adequada. Estas proporções mais adequadas foram determinadas comparativamente dentre os atributos do Teste de Panificação, não tendo sido estabelecidos limites mínimos de pontuação, como os citados por CAMARGO et al [3] para pães de trigo.

Os volumes específicos e as pontuações totais de cada mistura avaliada de farinha de arroz com vital glúten e farinha de aveia com vital glúten em comparação com a farinha de trigo são mostrados nas Tabelas 2 e 3. 
TABELA 2. Resultados dos Testes de Panificação de diferentes misturas de farinha de arroz com vital glúten

\begin{tabular}{lcc}
\hline \multicolumn{1}{c}{ Misturas } & $\begin{array}{c}\text { Volume específico } \\
\left(\mathrm{cm}^{3} / \mathrm{g}\right)\end{array}$ & Pontuação total $^{1}$ \\
\hline $\begin{array}{l}\text { 90\% farinha de arroz + 10\% glúten } \\
\text { (absorção de água: } 70 \% \text { - 500UF) }\end{array}$ & 1,42 & 25,2 \\
$\begin{array}{l}\text { 85\% farinha de arroz + 15\% glúten } \\
\text { (absorção de água: } 75 \% \text { - 500UF) }\end{array}$ & 1,78 & 32,9 \\
$\begin{array}{l}\text { 82,5\%farinha de arroz + 17,5\% glúten } \\
\text { (absorção de água: } 77 \% \text { - 500UF) }\end{array}$ & 2,67 & 51,9 \\
$\begin{array}{l}80 \% \text { farinha de arroz + 20\% glúten } \\
\text { (absorção de água: } 77 \%-500 U F)\end{array}$ & - & 38,0 \\
$70 \%$ farinha de arroz + 30\% glúten \\
(absorção de água: $77 \%$ - 500UF)
\end{tabular}

O volume específico e a pontuação total do Teste de Panificação para a adição de vital glúten na farinha de arroz (Tabela 2) seguem um comportamento parabólico com o valor máximo em $17,5 \%$ de vital glúten. As amostras provenientes das misturas com $20 \%$ e $30 \%$ de vital glúten perderam a estrutura na saída do forno, não permitindo a medida de volume dos pães. Desta forma, as pontuações totais referentes a essas misturas não incluem os pontos correspondentes à avaliação do volume específico.

No caso das misturas de farinha de aveia com vital glúten avaliadas pelo Teste de Panificação em comparação com a farinha de trigo, a adição de água até consistência de $500 U$. F. deu origem a massas pegajosas que não permitiram a perfeita moldagem.

Embora o volume específico e, conseqüentemente, a pontuação total dos pães feitos a partir da mistura com $30 \%$ de vital glúten sejam superiores aos dos pães com $20 \%$ de vital glúten (Tabela 3), seu aspecto foi afetado devido ao crescimento excessivo durante o assamento e posterior perda da estrutura, tornando os pães muito assimétricos e com aparência bastante prejudicada.

TABELA 3. Resultados dos Testes de Panificação de diferentes misturas de farinha de aveia com vital glúten

\begin{tabular}{lcc}
\hline \multicolumn{1}{c}{ Misturas } & $\begin{array}{c}\text { Volume específico } \\
\left(\mathrm{cm}^{3} / \mathrm{g}\right)^{1}\end{array}$ & Pontuação total $^{1}$ \\
\hline $\begin{array}{l}\text { 90\% farinha de aveia + 10\% glúten } \\
\text { (absorção de água: } 85 \% \text { - 720UF) }\end{array}$ & 1,66 & 29,0 \\
$\begin{array}{l}\text { 90\% farinha de aveia + 10\% glúten } \\
\text { (absorção de água: } 104 \% \text { - 650UF) }\end{array}$ & 2,30 & 34,7 \\
$\begin{array}{l}\text { 80\% farinha de aveia + 20\% glúten } \\
\text { (absorção de água: } 105 \% \text { - 650UF) }\end{array}$ & 3,07 & 44,7 \\
70\% farinha de aveia + 30\% glúten & 4,19 & 46,4 \\
(absorção de água: $105 \%$ - 650UF) & & \\
\hline
\end{tabular}

3.4 - Caracterização reológica das misturas de amido de trigo e das farinhas de arroz e de aveia com vital glúten em comparação com a farinha de trigo

Os parâmetros farinográficos e extensográficos das farinhas de trigo e de aveia e das misturas de amido de trigo, farinha de arroz e de aveia com vital glúten são mostrados na Tabela 4.
Os resultados do farinógrafo e do extensógrafo da farinha de trigo confirmaram que a mesma apresentava as características adequadas para a produção de pão: alta estabilidade (17,5 minutos) e baixo índice de tolerância à mistura (40U. F.); extensibilidade (138mm), resistência à extensão (700U. E.), além do valor de energia elevada $\left(152,3 \mathrm{~cm}^{2}\right)$.

A massa obtida a partir da farinha de aveia apresentou-se muito pegajosa, não permitindo o boleamento e a moldagem feitos no extensógrafo ou mesmo manualmente. Também não foi possível a obtenção dos parâmetros farinográficos e extensográficos da farinha de arroz pois, durante a análise não houve a formação de uma massa coesa que permitisse o registro da consistência correta pelo farinógrafo.

Quanto aos parâmetros farinográficos das misturas das farinhas analisadas, a absorção de água foi superior à da farinha de trigo, principalmente no caso da mistura com farinha de aveia $(108,2 \%)$ devido ao conteúdo de fibras desse cereal. Os demais parâmetros apresentaram valores característicos de farinhas fortes. Entretanto, para a mistura de farinha de aveia com vital glúten, os parâmetros extensográficos mostraram que, apesar dos valores de resistência e de resistência máxima estarem próximos aos da farinha de trigo (660U. E. e 830U.E. contra 700U. E. e 830U. E.), a massa apresentou baixa extensibilidade e área da curva consideravelmente inferior $\left(66,4 \mathrm{~cm}^{2}\right.$ contra $\left.152,3 \mathrm{~cm}^{2}\right)$, demonstrando que a mistura não apresentava as características ideais para a produção de pão.

Durante o ensaio da mistura de farinha de arroz com vital glúten no extensógrafo, a massa apresentou-se com aspecto quebradiço não permitindo o boleamento e a moldagem feitos no extensógrafo. Assim, estas etapas foram realizadas manualmente. A massa apresentou alta resistência (acima de 100U. E.), porém com esticamento mínimo até o seu rompimento. Como a massa não apresentou nenhuma elasticidade, o valor obtido não significou alta resistência à extensão, não sendo, portanto, a mistura adequada para a produção de pão.

TABELA 4. Caracterização reológica das farinhas de trigo e de aveia e das misturas de amido de trigo e das farinhas de arroz e de aveia com vital glúten

\begin{tabular}{lccccc}
\hline \multicolumn{1}{c}{ Análises } & \multicolumn{5}{c}{ Farinha } \\
\cline { 2 - 6 } & Trigo & $\begin{array}{c}\text { Amido } \\
\text { trigo }+ \\
\text { glúten }\end{array}$ & $\begin{array}{c}\text { Arroz }+ \\
17,5 \% \\
\text { glúten }\end{array}$ & Aveia & $\begin{array}{c}\text { Aveia + } \\
20 \% \\
\text { glúten }\end{array}$ \\
\hline Farinograma & & & & & \\
Absorção (\%) & 56,8 & 50,7 & 64,8 & 89,8 & 108,2 \\
Tempo de chegada (min) & 1,0 & 0,5 & 6,5 & 2,5 & 11,0 \\
Tempo de desenvolvimento & 9,5 & 7,0 & 13,0 & 3,5 & 22,5 \\
(min) & & & & & \\
Estabilidade (min) & 17,5 & 7,0 & 17,5 & 3,0 & 20,0 \\
Tempo de saída (min) & 18,5 & 7,5 & 24,0 & 5,5 & 31,0 \\
Índice de Tolerância à Mistura & 40 & 20 & 30 & 80 & 40 \\
(UF) & & & & & \\
Extensograma & & & & & 660 \\
Resistência à extensão (UE) - R & 700 & 520 & $>1000$ & - & 630 \\
Resistência máxima (UE) - Rm & 830 & 760 & $>1000$ & - & 62 \\
Extensibilidade (mm) - E & 138 & 54 & 62 & - & 66,4 \\
Energia (cm ${ }^{2}$ ) & 152,3 & 52,3 & $>94,8$ & - & 66,6 \\
Número proporcional - D & 5,1 & 9,6 & $>16,13$ & - & 10,6 \\
\hline
\end{tabular}


A reconstituição da farinha de trigo com vital glúten deu origem a uma mistura com características farinográficas inferiores às da farinha de trigo original (50,7\% absorção contra $56,8 \%$ e 7,0 minutos de estabilidade contra 17,5 minutos). Quanto às características extensográficas, enquanto os valores obtidos para a resistência à extensão e para a resistência máxima podem ser considerados característicos de farinha para pão, a extensibilidade diminuiu bastante, com conseqüente diminuição da área da curva. Farinhas com estas características dão origem a pães pesados e de baixo volume por não permitirem a expansão adequada da massa durante a etapa de fermentação.

3.5 - Qualidade panificável das misturas de amido de trigo e das farinhas de arroz e de aveia com vital glúten em comparação com a da farinha de trigo

Os resultados completos dos Testes de Panificação das misturas de amido de trigo e das farinhas de arroz e de aveia com vital glúten que apresentaram melhor desempenho são mostrados na Tabela 5, em comparação com o produto padrão, obtido a partir de farinha de trigo. Os pães obtidos a partir da farinha de trigo apresentaram volume específico de $5,15 \mathrm{~cm}^{3} / \mathrm{g}$, bem superior aos obtidos pelas misturas de farinha de arroz e de aveia com vital glúten $\left(2,67\right.$ e $3,07 \mathrm{~cm}^{3} / \mathrm{g}$, respectivamente).

TABELA 5. Avaliação da qualidade panificável das misturas de amido de trigo e das farinhas de arroz e de aveia com vital glúten por meio do Teste de Panificação, em comparação com a farinha de trigo

\begin{tabular}{|c|c|c|c|c|c|}
\hline \multirow[b]{2}{*}{ Características } & \multirow[b]{2}{*}{$\begin{array}{c}\text { Valor } \\
\text { máximo }\end{array}$} & \multicolumn{4}{|c|}{ Produto } \\
\hline & & $\begin{array}{c}\text { Farinha } \\
\text { trigo }\end{array}$ & $\begin{array}{l}\text { Amido trigo } \\
+ \text { glúten }\end{array}$ & $\begin{array}{c}\text { Far. arroz } \\
17,5 \% \text { glúten }\end{array}$ & $\begin{array}{l}\text { Far. aveia } \\
20 \% \text { glúten }\end{array}$ \\
\hline \multicolumn{6}{|l|}{ Externas } \\
\hline Volume $^{(*)}$ & 20 & 17,15 & 13,76 & 8,89 & 10,22 \\
\hline Cor da crosta & 10 & 7,5 & 8,0 & 7,0 & 8,0 \\
\hline Quebra & 5 & 4,0 & 1,5 & 0,5 & 0,5 \\
\hline Simetria & 5 & 4,5 & 4,5 & 2,5 & 2,0 \\
\hline \multicolumn{6}{|l|}{ Internas } \\
\hline Características da crosta & 5 & 3,5 & 2,5 & 1,5 & 2,5 \\
\hline Cor do miolo & 10 & 8,0 & 6,0 & 8,0 & 2,0 \\
\hline Estrutura do miolo & 10 & 8,0 & 5,0 & 3,0 & 3,0 \\
\hline Textura do miolo & 10 & 8,5 & 6,0 & 6,0 & 8,0 \\
\hline \multicolumn{6}{|l|}{ Aroma e Sabor } \\
\hline Aroma & 10 & 9,5 & 7,5 & 7,5 & 3,0 \\
\hline Sabor & 15 & 14 & 9 & 7 & 5,5 \\
\hline Pontuação total & 100 & 84,7 & 63,8 & 51,9 & 44,7 \\
\hline
\end{tabular}

No que diz respeito às demais características externas, as maiores diferenças entre os pães das misturas de farinha de arroz e de aveia em relação ao de farinha de trigo foram a pouca simetria e a quebra praticamente inexistente. Quanto às características internas, as principais diferenças foram a pouca formação de crosta e o miolo com alvéolos bem pequenos nos pães com farinha de arroz + vital glúten e de tamanho irregular nos pães com farinha de aveia + vital glúten, conforme ilustra a Figura 1. O miolo dos pães de farinha de aveia + vital glúten mostrou-se mais escuro, o que resultou em uma baixa pontuação neste parâmetro. O mesmo ocorreu com o aroma e o sabor próprios de aveia nesses pães e com o sabor adocicado dos pães com farinha de arroz + vital glúten. Embora diferentes do pão convencional de trigo, o que causou a diminuição da pontuação total no Teste de Panificação, essas características próprias das matérias-primas empregadas não podem ser consideradas depreciativas para os produtos, uma vez que foram consideradas aceitáveis.

Com relação aos pães obtidos da mistura de amido de trigo com vital glúten, verificou-se um volume menor do que o dos pães padrão, pouca quebra e miolo ligeiramente acinzentado, com estrutura compacta e alvéolos pequenos (Figura 1) o que contribuiu para uma textura menos macia. $\mathrm{O}$ aroma e o sabor foram considerados mais fracos que os dos pães padrão.
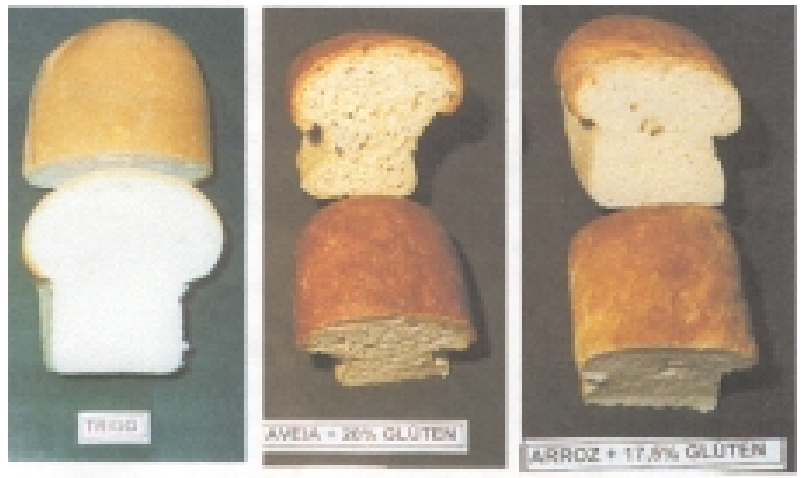

FIGURA 1. Amostras de pães analisados por meio do Teste de Panificação, produzidos com amido de trigo + vital glúten, farinha de aveia $+20 \%$ de vital glúten e farinha de arroz + $17,5 \%$ de vital glúten em comparação com os pães produzidos com farinha de trigo.

\section{4 - CONCLUSÕES}

- A partir dos resultados finais obtidos nos Testes de Panificação, verificou-se que a adição de vital glúten às farinhas de arroz e de aveia, nas proporções que apresentaram melhores resultados $(17,5 \%$ e $20,0 \%$, respectivamente), mostrou-se viável tecnicamente pois, apesar dos pães obtidos serem inferiores ao produto padrão, eles foram considerados aceitáveis. Por outro lado, os resultados superiores dos pães obtidos da farinha de trigo reconstituída com vital glúten em relação aos pães das misturas de farinha de arroz e de aveia levam à conclusão de que não apenas o glúten, mas outros componentes próprios da farinha de trigo são necessários para a obtenção de produtos de boa qualidade.

- A perda de qualidade dos produtos feitos com a farinha reconstituída com vital glúten quando comparados com os produtos feitos com a farinha original pode ser resultado da menor interação do vital glúten adicionado com os demais componentes da farinha de trigo, e, também da menor qualidade 
de vital glúten em relação ao próprio glúten da farinha de trigo. Novos estudos deverão ser feitos objetivando compreender como o glúten presente na farinha interage com os demais componentes.

\section{5 - REFERÊNCIAS BIBLIOGRÁFICAS}

[1] AMERICAN ASSOCIATION OF CEREAL CHEMISTS. Approved Methods, 8th ed., vol. I e II, AACC, St. Paul, 1990.

[2] ASSOCIATION OF OFFICIAL ANALYTICAL CHEMISTS. Official Methods of Analysis, $14^{\text {th }}$ ed, AOAC, Washington, 1984.

[3] CAMARGO, C.E.O.; CAMARGO, C.R.O.; FELÍCIO, J.C.; FERREIRA FILHO, A.W.P.; SANTOS,R.R.; DECOT, G. Avaliação das características agronômicas e tecnológicas de genótipos de trigo duro, trigo e triticale. Boletim Científico do Instituto Agronômico, n.29, p.127, 1993.

[4] CAPRONI, E.; BONAFACCIA, G. Azione del glutine vitale su alcune caratteristiche reologiche degli impasti di sfarinati di tenero. Tecnica Molitoria, v.40, n.7, p.497-5012, 1989.
[5] CZUCHAJOWSKA, Z.; PASZCZYÑSKA, B. Is wet gluten good for baking? Cereal Chemistry, v.73, n.4, p.483-489, 1996.

[6] EL-DASH, A.A. Standardized mixing and fermentation procedure for experimental baking test. Cereal Chemistry, v.55, n.4, p. 436-446, 1978.

[7] HE, H.; HOSENEY, R.C. Gas retention of different cereal flours. Cereal Chemistry, v.68, n.4, p. 334 - 336, 1991.

[8] HOSENEY, R.C. Principles of Cereal Science and Technology. St. Paul: American Association of Cereal Chemists, AACC, 1990, p.76-87.

[9] LOCKART, V.B.; HURT, D. Nutrition of oats. In: WEBSTER, F. H. Oats: Chemistry and Technology. St. Paul, Minessota, USA. American Association of Cereal Chemists, AACC, 1986, p. 297-308.

[10] MAGNUSON, K. M. Uses and functionality of vital wheat gluten. Cereal Foods World, v. 30, n.2, p. 179-181, 1985.

[11] RANHOTRA, G.S.; GELROTH, J.A.; EISENBRAUN, G.J. Gluten index and bread-making quality of commercial dry glutens. Cereal Foods World, v. 37, n. 3, p. 261-263, 1992.

[12] STENVERT, N. L.; MOSS, R.; MURRAY, L. The role of dry vital wheat gluten in breadmaking. Part I. Quality Assessmente and mixer interaction. Bakers Digest, v.55, n. 2, p. 6-12, 1981. 